\title{
Severe acute alcoholic hepatitis and liver transplant: A never-ending mournful story
}

\author{
Aiman Obed ${ }^{1}$, Abdalla Bashir ${ }^{1}$, Steffen Stern², and Anwar Jarrad ${ }^{3}$ \\ 'Division of General, Hepatobiliary and Transplant Surgery, Jordan Hospital, Amman, Jordan; 'Faculty of Law, Bielefeld University, \\ Bielefeld, Germany; ${ }^{3}$ Division of Gastroenterology, Jordan Hospital, Amman, Jordan
}

Severe acute alcoholic liver disease (SAAH) unresponsive to medical therapy shows one-year-mortality rates of up to $90 \%$. Most transplant centers request six months of alcohol abstinence prior to transplantation, the so-called "6-month rule." This regulation is not based on strong evidence, repeatedly making it a topic of controversial debates. The majority of patients with SAAH will die before fulfilling the 6-month rule. Therefore, liver transplantation (LT) protocols are becoming more flexible towards the rigid abstinence regulation, especially concerning SAAH patients. We conducted a literature review regarding LT in SAAH and its outcomes, including post-transplant mortality and recidivism. We studied available data on PubMed from 2011 and onwards whilst including articles dealing with genetic components, medical therapy and historic snapshots of alcoholism. Emerging studies recommend LT in SAAH not responding to medical therapies even without realizing the required abstinence period, since the majority of these patients would die within 6 months. SAAH without response to medical therapy has one-year-mortality rates of up to $90 \%$. The 6-month rule is not based on strong evidence and is repeatedly a topic of controversial debates. There is genetic linkage to alcoholism and medical therapy is not as effective as estimated, yet. The 6-months-regulation has not shown to evidently decrease the risk of recidivism post-LT, which is a lifesaving treatment in SAAH patients. Insisting on rigid sobriety rules results in excluding patients with a low risk of recidivism from being transplanted. Moreover, the genetic linkage of alcoholism must be recognized. (Clin Mol Hepatol 2018;24:358-366)

Keywords: Liver failure; Alcoholic hepatitis; Cirrhosis; Hepatocellular carcinoma; Liver transplantation

\section{INTRODUCTION}

All human organs could be damaged by alcohol, with various clinical presentations. Somatically, alcohol can damage the circulatory, nervous, hepatic, pancreatic and gastroenterological systems.' In our opinion, abstinence from alcohol in patients with liver disease is wise and medically advantageous. The link between alcohol abuse and liver disorder has been recognized for decades.
Liver injury from alcoholic liver diseases (ALD) can present as simple liver damage, fatty liver, steatohepatitis, fibrosis, cirrhosis, hepatocellular carcinoma or cholangiocarcinoma.

Severe acute alcoholic hepatitis (SAAH) is a known entity within the spectrum of chronic ALDs. In general, it occurs in certain cases of extensive alcohol abuse. SAAH frequently presents with other signs of liver failure including encephalopathy, jaundice, ascites and fatigue. ${ }^{2}$ White blood cell count, international normalized ra-

\section{Abbreviations:}

ALD, alcoholic liver dieseases; LT, liver transplantation; NASH, non alcoholic steatohepatitis; SAAH, severe acute alcoholic hepatitis

\section{Corresponding author : Aiman Obed}

Division of General, Hepatobiliary and Transplant Surgery, Jordan Hospital, Queen Nour Street, P.O. Box 520248, Amman 11152, Jordan

Tel: +962-6-5608030, Fax: +962-6-5608030

E-mail: aimanobed@hotmail.com

https://orcid.org/0000-0001-7519-9868 
tio, neutrophil count and total serum bilirubin levels are typically abnormal. Mortality risk in patients with alcoholic hepatitis can be calculated using the Maddrey discriminant function., ${ }^{3,4}$ The incidence of SAAH is associated with short-term mortality greater than $70 \%$ in patients who failed glucocorticoid therapy. ${ }^{5}$ SAAH presents in young patients.

Many historic publications in the literature consider SAAH as a contraindication for liver transplantation (LT) secondary to the assumption of immediate and current alcohol use. Unfortunately, the 6-month survival is less than $25 \%$ in those that do not respond to steroids and do not receive liver transplants. In this study, we reviewed the recent literature regarding SAAH patients who undergo LT.

The abstinence rule for alcoholic cirrhosis was suggested in order to make room for the improvement of liver functions from severe injury due to alcoholism. ${ }^{6}$ Twenty years ago, this became an overall obligation. ${ }^{7.8}$ Later on, this rule has also been used to define the risk of recidivism after liver transplantation.

There are two main arguments for the contraindication of $L T$ in SAAH. First, precious organs should not be given to patients whose behavior caused liver injuries through self-harm. Secondly, the possibility of recidivism is high in patients who have had a history of alcohol addiction leading to urgent liver transplant.

The argument of contraindication for $\mathrm{LT}$ in those who are engaging in self-harm up to the point of transplantation is biased towards alcohol as the substance of abuse. Rescue LT is broadly accepted in patients with suicidal driven excessive acetaminophen or ecstasy ingestion resulting in acute hepatic failure. In addition, LT for patients with fulminant viral hepatitis caused by past drug use is accepted. ${ }^{9-12}$ In contemporary times, nonalcoholic fatty liver disease (NASH) caused by obesity encompasses a significant majority of liver failure requiring LT.

Rejection of life-preserving treatment on biased judgmental decisions depicts a violation of Article 25 of the Universal Declaration of Human Rights which ensures patients' fundamental right to treatment without discrimination. There are mounting arguments in the literature questioning the basis of denial of $L T$ in SAAH, particularly with regards to the 6 -month rule.

\section{MEDICAL THERAPY}

Medical therapy for severe alcoholic hepatitis (AH) has mainly alternated between two drugs, steroids and pentoxifylline, which have been suggested in several treatment strategies. ${ }^{3,13,14}$ Since the first major study representing survival benefit with corticosteroid therapy by Maddrey et al., only little change has occurred in the medical therapy of $\mathrm{AH} .{ }^{15}$ Over the last years, steroids have remained the basis of medical therapy for severe $\mathrm{AH}$, even though the results that backup the positive effect are mixed. The largest study on SAAH, the steroids or pentoxifylline for alcoholic hepatitis (STOPAH) trial, found that corticosteroid therapy was associated with a tendency to reduce 28-day mortality, with a total reduction of death occurrence of $4 \%$. Nevertheless, this benefit did not continue at 90 days or 1 year. ${ }^{16}$ The possible reason for this deviation could be that patients were younger and were less frequently affected by hepatic encephalopathy compared to patients in the most current trials.

To recognize the subgroup of patients that would eventually not respond to therapy, early change in bilirubin levels at 1 week from the start of treatment and the Lille model were developed. A Lille score of $\leq 0.45$ is considered a good response to corticosteroid therapy whereas a score of $>0.45$ is considered as non-response. In non-responders, steroids should be stopped to avoid negative consequences. Moreover, the six-month mortality is approximately $15 \%$ for patients who respond to therapy; it rises to over $75 \%$ for non-respondents. ${ }^{17}$ Thus, the non-responders to steroids remain at enormously extreme risk of short-term mortality.

Pentoxifylline, with its superior safety profile, was seen as an attractive alternative to steroids; especially within the subset of patients not responding to steroids. ${ }^{18}$ Pentoxifylline, a methylxanthine, mitigates the production of tumor necrosis factor alpha that plays a role in the pathogenesis of $\mathrm{AH}^{19}{ }^{19}$ Common side effects contain diarrhea, vomiting and headache leading to medicine cessation. ${ }^{20}$ In many studies and randomized trials, pentoxifylline revealed inferiority compared to steroids in terms of survival benefit. ${ }^{21}$ Additionally, the STOPAH trial showed no benefit of pentoxifylline over placebo in preventing short-term mortality in severe $\mathrm{AH}^{16}$

In a multi-center study of more than 170 patients, the use of IV $\mathrm{N}$-acetylcysteine in combination with corticosteroids was compared with steroids alone; one-month-survival was superior in the combination group. However, there was no survival benefit after 3 or 6 months. ${ }^{22}$

\section{ALD AND THE LONG WAY OF SORROW}

The need for $L T$ in ALD patients is wrought with misperceptions and is not taken seriously enough by physicians and the general public. As previously mentioned, bias towards alcohol as sub- 
stance abuse of choice increasingly leads to judgmental arguments excluding those patients with ALD from potentially lifesaving LT. Alcohol use in certain countries in the world is officially forbidden for religious reasons, such as in Muslim countries. Other countries in which the consumption of alcohol is legal have handed severe punishments for extreme use. For example, during the National Socialist regime in Germany, alcoholics have been sterilized and even killed within the legal frame of Action T-4, which called for "the termination of the mentally ill and handicapped patients" by Nazi authorities. Alcohol was seen as a "genetic poison," leading to the deterioration of the people of the nation. In July 1933, the "Law for the Prevention of Hereditarily Diseased Offspring" legalized compulsory sterilization for chronic alcoholism, then categorized as a form of social abnormalty. ${ }^{23,24}$

We believe, that the denial of LT in SAAH patients, who have failed medical therapy and have not fulfilled the 6 -month abstinence rule, is grounded in part on these historically based preperceived prejudices regarding alcoholics and their "un-worthiness" for transplantation.

After World War II, Germany's constitution was based on progressive ideals; especially with regards to healthcare, recognizing it as an inalienable human right. Modern medical treatment is guaranteed for citizens regardless of religious beliefs, race or ethnicity. This is upheld in the German Federal Constitutional Court and is applied equally throughout the population. In the European Union, the United States and other democratic nations consider the discrimination of individuals and groups a crime.

Welch first suggested LT as a possible treatment for fulminant hepatic failure in $1955 .{ }^{25}$ In 1958, Francis Moore described the first orthotopic LT in dogs. ${ }^{26}$ By 1963 Starzl performed the first LT in the world in a 3-year-old child with biliary atresia. ${ }^{27}$ In 1975 , Starzl depicted that patients with ALD, free of infectious or other complications, are suitable liver recipients. ${ }^{28}$ Despite, the majority of transplant centers began demanding a 6 -month abstinence period prior to LT. Strazl harshly criticized this obligatory 6 -month rule in 1988, alluding to a lack of any scientific basis and highlighting the unsound and inhumane character of its implementation. He reasoned that delaying the LT would cause appropriate candidates to deteriorate into high-risk classification, and those patients would certainly die during the waiting period..$^{29}$ Additionally, he emphasized that using expenses as an argument against LT would be equally illogical, unless an even more drastic decision would be taken to refuse all treatment from patients dying of alcohol cirrhosis and perhaps other liver illnesses. ${ }^{29}$ Public opinion along with physicians and specialists recognized that the segrega- tion of these patients from an adequate therapy poses a significant harm to patients and violates their rights. SAAH patients deserve to participate in a deceased donation system as human dignity and human rights relate to all. This discrimination against a smaller group of very ill patients cannot continue and we must recognize our ethical and moral duty in regards to this patient population.

\section{ALD AND GENETIC ASSOCIATION}

Alcohol use disorder (AUD) is a chronic psychiatric disease categorized by toxic drinking patterns causing negative emotional, physical and social consequences. Although the contributing pathophysiology of AUD is poorly understood, there is considerable evidence of a genetic factor. AUD is a complex illness, and probably hundreds, if not thousands of genes contribute to its wide and varied phenotype. ${ }^{30}$ Based on earlier association studies, the strongest links have been identified in the alcohol metabolism genes; alcohol dehydrogenase (ADH) and aldehyde dehydrogenase (ALDH). Alcohol metabolism is a two-step process where ADH first oxidizes ethanol to acetaldehyde and then is additionally oxidized to acetate by ALDH. Accumulation of the toxic intermediate acetaldehyde can cause adverse physiological symptoms, including flushing syndrome, tachycardia, and nausea. ${ }^{31}$ Research using family and twin studies was the first to demonstrate the role of genetics in AUD. The Australian twin-family study of AUD found a greater concordance of alcohol addiction in monozygotic (56\% for males) compared to dizygotic twins (33\% for males) and a heritability estimate of $64 \% .^{32-34}$

Understanding the genetic basis could be significant in monitoring personalized treatments of patients who have established AUD and to guide new pharmacological treatments. Frank et al. presented the first genome-wide connection study of alcohol dependence (AD) to deliver genome-wide significant backing for the role of the ADH gene cluster. ${ }^{34}$ This led to the proposition of a polygenic component to the etiology of $A D$, which might show that many further $A D$ susceptibility genetic factors still await identification. ${ }^{35}$ Genetic factors in ALD and alcoholism are increasingly recognized which could be applied to the treatment of SAAH patients. This is best attempted through a multidisciplinary approach including psychiatrists and addiction professionals with the main focus on the posttransplant phase. 


\section{DISCUSSION}

Alcohol is a hepatic toxin that is consumed globally and is connected to a wide range of liver injuries including simple steatosis, fatty liver, alcoholic hepatitis, fibrosis and cirrhosis. Excessive alcohol use is recognized as a significant risk factor for morbidity and mortality globally. ${ }^{36}$ All patients who present with clinical features of hepatitis or chronic liver disease or who have elevated serum transaminase levels should be screened for an alcohol use disorder. The diagnosis of ALD can generally be made based on history, along with supporting clinical and laboratory findings. However, the diagnosis of ALD can be clinically challenging as there is no single test that confirms the diagnosis and patients may not be cooperative about their degree of alcohol consumption. In addition, clinical findings may be absent or minimal in early ALD characterized by hepatic steatosis. Typical laboratory findings in ALD can include elevated levels of aspartate aminotransferase and gamma-glutamyl transpeptidase. In unclear cases, the diagnosis can be supported by liver biopsy and imaging. The histological examination of ALD is characterized hepatic steatosis, inflammation and the visualization of Mallory bodies.

In the past, limited retrospective studies have evaluated the usefulness of treating alcohol addiction either previously or after LT. However, some liver transplant centers and numerous insurance companies required 6 months of abstinence from alcohol as a qualification of suitability for $\mathrm{LT}^{37-39}$ Insurance companies should not be involved in medical issues regarding diagnostic and treatment for very ill patients secondary to a potential conflict of interest. As there is no further treatment apart from $L T$ in patients with SAAH not responding to medical therapy, the 6-month rule could be lethal in some circumstances. In this study we reviewed the literature in regards to the 6 -month rule and SAAH patients who undergo LT.

The precondition phase of alcohol abstinence for the transplant suitability in SAAH patients who failed medical treatment seems ethically unfair, as the majority of these patients will die before they reach the requested six-month abstinence phase.

Consequently, denying these patients a potentially life saving treatment is morally intolerable. Despite the convincing outcome, major disagreement persists regarding LT prior to the six months rule. It is still mandated by most liver transplant centers worldwide. ${ }^{40-44}$ This is concerning as mounting evidence shows that when there is fulminant hepatic failure, abstinence has no influence on patient survival. ${ }^{45,46}$

In the past, public opinion usually did not encourage LT for pa- tients with SAAH. Some publications revealed that public support for LT was greater for other diseases than for diseases such as ALD. ${ }^{47-49}$ Accordingly, the transplant society was worried that people will be less willing to donate if their organs will be allocated to patients with ALD. This was shown in the scarcity of $L T$ for ALD in the 1980s and 1990s. But today, public opinion is evolving and appears to change towards offering more support for therapy to all individuals as alcoholism is increasingly seen as a multi-factorial illness. . $^{50-54}$

Since 2011, we have witnessed an increasing number of evidence-based publications in favor of abolishing the 6-month-rule, part of which were randomized studies. Mathurin et al. ignited the initiation of this development. ${ }^{5}$

The breakthrough multicenter study by Mathurin et al. from France indicated a substantial survival benefit in patients with SAAH not responding to glucocorticoid therapy by early LT in carefully selected patients. ${ }^{5}$ They displayed mortality rates for patients with SAAH from the 7th to the 14th day of intensive care unit (ICU) admission. According to their results, an absence of clinical development in patients with SAAH in the first 2 weeks of ICU treatment suggests an inferior result and the essential requirement for LT. In less than $3 \%$ of the patients assessed with SAAH and nominated to undergo LT the 6 -month survival was $77 \%$ vs. $23 \%$ in corresponding controls $(P<0.001)$, while only three of the 26 transplanted patients resumed alcohol consumption during follow-up time.

Inspired by Mathurin and colleagues, Testino et al. published an Italian position statement, which represents numerous Italian transplant centers and the World Health Organization Collaborating Centre for Research and Health Promotion in Italy. ${ }^{54}$ They openly support and advance adopting an approach similar to their French colleagues. ${ }^{54}$ Testino et al. concluded that the "6-month rule" is not evidence-based and LT is compulsory in selected patients, irrespective of the sober period realized..$^{54}$

Also stimulated by the French study, a significant randomized US study, published by Im et al. intended to find out if a strategy of early LT for SAAH might be implemented successfully in the United States.$^{55}$ They evaluated 111 patients with SAAH between 2012 and 2015. The primary end point was mortality at 6 months or early LT, with a secondary end point of alcohol relapse after LT.

Just $9(9.6 \%)$ patients with positive psychosocial assessments experienced early LT, including $3 \%$ of all adult LT during the study period. The 6-month survival rate was higher among those who received early LT compared with matched controls (89\% vs. $11 \%$, $P<0.001)$. Eight patients who received LT were alive after a medi- 
an of 24 months with single alcoholic relapse. Im et al. ${ }^{55}$ have demonstrated huge survival benefit and reproducible outcomes similar to those by Mathurin et al. ${ }^{5}$

Im et al. ${ }^{55}$ and Mathurin et al. ${ }^{5}$ revealed that SAAH patients transplanted in their published studies, included only $1.4-2.4 \%$ of the liver donor pool, implying that this number does not significantly affect the post-mortal organ pool, especially considering the fact that the number of LTs for hepaptitis C virus-patients will most probably decrease within the next few years.

Further reviews and studies followed; on behalf of the International Liver Transplant Society, Addolorato et al. strongly recommended to offer $\mathrm{LT}$ to selected SAAH patients in their recent publication. ${ }^{56}$ In 2017, Testino et al. published two review articles, recommending that under the condition in which SAAH patients did not respond to corticosteroid therapy, LT becomes a vital treatment to significantly improve survival. LT after appropriate selection must be proposed for both prognostic and ethical reasons. $^{57,58}$

Within the last years, guidelines concerning alcohol use have become more flexible; particularly towards patients with SAAH. Despite the fact that policies considering alcohol have changed significantly in the last decade, they remain extremely variable among liver transplant centers. Zhu et al. conducted a study including a questionnaire to 100 UNOS-approved liver transplant centers in North America that have done at least thirty organ transplants each year in the last 5 years. ${ }^{59}$ Surprisingly, concerning SAAH patients, $71 \%$ of US transplant centers would waive the 6-month abstinence obligation in those with favorable psychosocial factors such as family support, patient's motivation or commitment to rehabilitate. Furthermore, active methadone consumers were accepted in $45 \%$ of the US transplants centers. ${ }^{59}$

Jesudian et al. ${ }^{60}$ and Germani et al. ${ }^{61}$ recommended early LT in highly selected patients with SAAH not responding to medical therapy, since emerging studies demonstrated a strong survival advantage and positive posttransplant results. LT for refractory SAAH is a life-saving therapy and must be judiciously implemented in very designated patients who are at low risk of relapse.

Similarly motivated by the French study, an important randomized US study, published by Lee et al., proposed to find out, if a strategy of early LT for SAAH might be implemented successfully in the United States. ${ }^{62}$ Lee et al. published 2016 the results of a pilot study that carefully chose SAAH patients for LT. ${ }^{62}$ They found that early liver transplant led to excellent short-term survival rates and the recidivism rate was comparable with the patients in the six-month abstinence group. ${ }^{62}$
A recent review article published 2018 in an Indian transplant center strongly supported LT in SAAH patients. According them, $\mathrm{LT}$ is a definite treatment that can hypothetically offer long-term benefit for patients who are steroid non-responders.

The idea of self-inflicted illness is not an acceptable one. An urgent LT is accepted for patients with suicidal acetaminophen resulting in fulminant hepatic failure. On analogous lines, LT for patients with previous I.V. drug use causing viral hepatitis or obesity leading to NASH continue to form a major chunk of all LTs. The rejection of treatment on moral or judgmental motives is similar to robbing the patient of a fundamental right to treatment without discrimination. This kind of conflicting practice might dishonor the entire transplant system. Alcoholism is a sickness, and must be treated accordingly. ${ }^{63}$

Hong et al. published a retrospective study compering outcomes in patients undergoing LT for hepatitis B virus and ALD in Asian countries in which living-donor $L T$ is leading. ${ }^{64}$ There were no firm guidelines on pre-transplant abstinence for ALD. The transplant center in South Korea didn't dictate a minimum abstinence period prior to LT. A psychiatrist interviewed all patients and patients' families. Results showed that ALD patients have more psychiatric morbidities, other than alcohol reuptake, after transplantation. No patient in either group died of de novo tumors. De novo tumors occurred in only 4 patients (3.7\%) in the HBV group, but in none of the ALD group. They concluded, that outcomes of deceased donor liver transplantation were not inferior for patients with ALD than for HBV in an HBV endemic area, even in the absence of a fixed abstinence period before LT. The 1-year and 3-year overall survival rates were $94.1 \%$ and $89.4 \%$ in the HBV patients, and $90.6 \%$ and $79.1 \%$, in the ALD patients. These survival rates did not differ significantly. ${ }^{64}$

Simultaneously, medical law professionals sustain, albeit from a different point of view than those in real medicine, that constitutional law forbids discrimination against subgroups and life differentiations as being either worthy or unworthy of life. They stress that the exclusion of non-sober ALD patients from being listed discriminates them and violates said constitutional law. ${ }^{65}$

The United Network for Organ Sharing in the US has still accepted the 6-month rule, though it does advise that "exceptional" cases may be referred to regional review boards for consideration. The American Association for the Study of Liver Disease's current guidelines also recommend 6 months of no alcohol consumption before LT, but they stress that consumption is not a factor as to whether or not a patient is recognized as a candidate for a $\mathrm{LT}^{8}$

The 6-months regulation has not been shown to decrease recid- 
ivism risk post $\mathrm{LT}^{66,67} \mathrm{LT}$ is certainly lifesaving in SAAH patients, but insisting on rigid sobriety rules excludes patients with a low risk of recidivism from being transplanted. Moreover, alcoholism must be recognized as an illness with a genetic linkage. ${ }^{68-79}$

In our opinion, live-donor LT represents a development that is no longer dependent on the approachability of deceased donor organs. Those who oppose LT in severe acute ALD cannot debate that the procedure robs another patient of an appropriate organ, which is ethically and legally fundamentally wrong. Moreover, risks to the donor are true and the liver donation must only be carried out when there is a clear chance of a good result. In case of early post -transplant liver failure, for example in case of unexpected difficulties, the recipient must have" high urgency" legal access to deceased organ allocation system.

Last but least, we must be sensitized and acknowledge that the United Nations Universal Declaration of Human Rights states all human beings are born free and equal in terms of dignity and rights. Everyone has the right to life, liberty, security and a standard of living adequate for the health and well-being of themselves and their family. ${ }^{80}$

Finally, encouraging sparks of hope arose from some American transplant centers, which have started transplanting chosen patients with SAAH. In a study of 45 American transplant hospitals, 11 centers performed LT for patients with SAAH during the last 5 years, making up 45/3,290 (1.37\%) of total transplants at these centers. ${ }^{81}$ Marot et al. found that $14 \%$ of patients with clinically severe $\mathrm{AH}$ have an alcohol relapse after $\mathrm{LT}^{82}$ The percentage of alcohol relapse of $\mathrm{AH}$ transplanted patients is similar to that of patients who underwent elective $\mathrm{LT}^{82}$ Lee et al. ${ }^{83}$ conducted a retrospective analysis of 147 patients who underwent early LT for severe $\mathrm{AH}$; the patient's survival for 1 year (94\%) and 3 years (84\%) was comparable to that of patients receiving LT for other indications. Constant alcohol usage after LT was infrequent but related to increased mortality. Their findings support the selective use of $\mathrm{LT}$ as a treatment for severe $\mathrm{AH}{ }^{83,84}$ Antonini et al. showed an increased support among physicians for early transplantation in acute alcoholic hepatitis in a nationwide survey of French LT programs. $^{85}$

\section{CONCLUSION}

In conclusion, selection and allocation guidelines for SAAH, in particular the abstinence rule, must be appropriately reviewed in order to prevent further avoidable patient casualties. For SAAH patients who do not respond to medical therapy within 14 days after being admitted, LT must be considered, irrespective of realized abstinence period. A multidisciplinary approach including psychiatrics and addiction professionals is required, especially in the early post transplant period.

\section{Statement}

The authors declare that they did not receive any funding for this work. This article is submitted as an original article. This paper is not based on a previous communication to a society or meeting.

\section{Authors' contribution}

Study design: Aiman Obed

Data collection: Aiman Obed, Anwar Jarrad

Data interpretation: Abdalla Bashir, Anwar Jarrad

Manuscript preparation: Abdalla Bashir, Steffen Stern

Literature search: Aiman Obed, Steffen Stern

\section{Acknowledgment}

The authors thank Dr. Eftaiha Saleh (Department of Surgery, University of Illinois, Chicago, USA) for proof-reading.

\section{Conflicts of Interest}

The authors have no conflicts to disclose.

\section{REFERENCES}

1. Testino G. Alcoholic diseases in hepato-gastroenterology: a point of view. Hepatogastroenterology 2008;55:371-377.

2. Crawford JM. Vascular disorders of the liver. Clin Liver Dis 2010;14:635-650.

3. European Association for the Study of Liver. EASL clinical practice guidelines: management of alcoholic liver disease. J Hepatol 2012;57:399-420.

4. Sohail U, Satapathy SK. Diagnosis and management of alcoholic hepatitis. Clin Liver Dis 2012;16:717-736.

5. Mathurin P, Moreno C, Samuel D, Dumortier J, Salleron J, Durand F, et al. Early liver transplantation for severe alcoholic hepatitis. N Engl J Med 2011;365:1790-1800.

6. Hoofnagle JH, Kresina T, Fuller RK, Lake JR, Lucey MR, Sorrell MF, et al. Liver transplantation for alcoholic liver disease: executive statement and recommendations. Summary of a National Institutes of Health workshop held December 6-7, 1996, Bethesda, Maryland. 
Liver Transpl Surg 1997;3:347-350.

7. Tandon P, Goodman KJ, Ma MM, Wong WW, Mason AL, Meeberg $G$, et al. A shorter duration of pre-transplant abstinence predicts problem drinking after liver transplantation. Am J Gastroenterol 2009;104:1700-1706.

8. Leong J, Im GY. Evaluation and selection of the patient with alcoholic liver disease for liver transplant. Clin Liver Dis 2012;16:851-863.

9. Miguet M, Monnet E, Vanlemmens C, Gache P, Messner M, Hruskovsky $\mathrm{S}$, et al. Predictive factors of alcohol relapse after orthotopic liver transplantation for alcoholic liver disease. Gastroenterol Clin Biol 2004;28(10 Pt 1):845-851.

10. Donckier V, Lucidi V, Gustot T, Moreno C. Ethical considerations regarding early liver transplantation in patients with severe alcoholic hepatitis not responding to medical therapy. J Hepatol 2014;60:866871.

11. Neuberger J, Adams D, MacMaster P, Maidment A, Speed M. Assessing priorities for allocation of donor liver grafts: survey of public and clinicians. BMJ 1998;317:172-175.

12. Stroh G, Rosell T, Dong F, Forster J. Early liver transplantation for patients with acute alcoholic hepatitis: public views and the effects on organ donation. Am J Transplant 2015;15:1598-1604.

13. O'Shea RS, Dasarathy S, McCullough AJ. Alcoholic liver disease. Am J Gastroenterol 2010;105:14-32; quiz 33.

14. O'Shea RS, Dasarathy S, McCullough AJ; Practice Guideline Committee of the American Association for the Study of Liver Diseases; Practice Parameters Committee of the American College of Gastroenterology. Alcoholic liver disease. Hepatology 2010;51:307-328.

15. Maddrey WC, Boitnott JK, Bedine MS, Weber FL Jr, Mezey E, White RI Jr. Corticosteroid therapy of alcoholic hepatitis. Gastroenterology 1978;75:193-199.

16. Thursz MR, Richardson $P$, Allison M, Austin A, Bowers M, Day CP, et al. Prednisolone or pentoxifylline for alcoholic hepatitis. N Engl J Med 2015;372:1619-1628.

17. Louvet A, Naveau S, Abdelnour M, Ramond MJ, Diaz E, Fartoux L, et al. The Lille model: a new tool for therapeutic strategy in patients with severe alcoholic hepatitis treated with steroids. Hepatology 2007:45:1348-1354.

18. Louvet A, Diaz E, Dharancy $S$, Coevoet $H$, Texier $F$, Thévenot $T$, et al. Early switch to pentoxifylline in patients with severe alcoholic hepatitis is inefficient in non-responders to corticosteroids. J Hepatol 2008; 48:465-470.

19. Strieter RM, Remick DG, Ward PA, Spengler RN, Lynch JP 3rd, Larrick $J$, et al. Cellular and molecular regulation of tumor necrosis factoralpha production by pentoxifylline. Biochem Biophys Res Commun 1988;155:1230-1236.

20. Akriviadis E, Botla R, Briggs W, Han S, Reynolds T, Shakil O. Pentoxifylline improves short-term survival in severe acute alcoholic hepatitis: a double-blind, placebo-controlled trial. Gastroenterology

\section{0;119:1637-1648.}

21. Park SH, Kim DJ, Kim YS, Yim HJ, Tak WY, Lee HJ, et al. Pentoxifylline vs. corticosteroid to treat severe alcoholic hepatitis: a randomised, non-inferiority, open trial. J Hepatol 2014;61:792-798.

22. Nguyen-Khac E, Thevenot T, Piquet MA, Benferhat S, Goria O, Chatelain D, et al. Glucocorticoids plus N-acetylcysteine in severe alcoholic hepatitis. N Engl J Med 2011;365:1781-1789.

23. Lewy J. A sober Reich? Alcohol and tobacco use in Nazi Germany. Subst Use Misuse 2006;41:1179-1195.

24. Götz A, Peter C, Pross C. Cleansing the Fatherland: Contributions to National Socialist Health and Social Policy. 1st ed. Baltimore and London: Johns Hopkins University Press, 1994;978:0-8018-4775-2.

25. Welch CS. Liver graft. Maroc Med 1955;34:514-515.

26. Moore FD, Smith LL, Burnap TK, Dallenbach FD, Dammin GJ, Gruber $U F$, et al. One-stage homotransplantation of the liver following total hepatectomy in dogs. Transplant Bull 1959;6:103-107.

27. Starzl TE, Marchioro TL, Vonkaulla KN, Hermann G, Brittain RS, Waddell WR. Homotransplantation of the liver in humans. Surg Gynecol Obstet 1963;117:659-676.

28. Starzl TE, Putnam CW, Ishikawa M, Picache R, Husberg B, Halgrimson $C G$, et al. Current policies in hepatic transplantation: candidacy of patients with alcoholic liver disease or preformed antidonor antibodies and a reappraisal of biliary duct reconstruction. Ann N Y Acad Sci 1975;252:145-158.

29. Iwatsuki S, Starzl TE, Todo S, Gordon RD, Tzakis AG, Marsh JW, et al. Liver transplantation in the treatment of bleeding esophageal varices. Surgery 1988;104:697-705.

30. Tawa EA, Hall SD, Lohoff FW. Overview of the genetics of alcohol use disorder. Alcohol Alcohol 2016;51:507-514.

31. Heath AC, Bucholz KK, Madden PA, Dinwiddie SH, Slutske WS, Bierut LJ, et al. Genetic and environmental contributions to alcohol dependence risk in a national twin sample: consistency of findings in women and men. Psychol Med 1997;27:1381-1396.

32. Agrawal A, Lynskey MT. Are there genetic influences on addiction: evidence from family, adoption and twin studies. Addiction 2008;103:1069-1081.

33. Enoch MA. The role of early life stress as a predictor for alcohol and drug dependence. Psychopharmacology (Berl) 2011;214:17-31.

34. Frank J, Cichon S, Treutlein J, Ridinger M, Mattheisen M, Hoffmann P, et al. Genome-wide significant association between alcohol dependence and a variant in the ADH gene cluster. Addict Biol 2012;17:171-180.

35. Torruellas C, French SW, Medici V. Diagnosis of alcoholic liver disease. World J Gastroenterol 2014;20:11684-11699.

36. Bird GL, O'Grady JG, Harvey FA, Calne RY, Williams R. Liver transplantation in patients with alcoholic cirrhosis: selection criteria and rates of survival and relapse. BMJ 1990;301:15-17.

37. Kumar S, Stauber RE, Gavaler JS, Basista MH, Dindzans VJ, Schade 
RR, et al. Orthotopic liver transplantation for alcoholic liver disease. Hepatology 1990;11:159-164.

38. Osorio RW, Ascher NL, Avery M, Bacchetti P, Roberts JP, LakeJR. Predicting recidivism after orthotopic liver transplantation for alcoholic liver disease. Hepatology 1994;20(1 Pt 1):105-110.

39. Obed A, Stern S, Jarrad A, Lorf T. Six month abstinence rule for liver transplantation in severe alcoholic liver disease patients. World J Gastroenterol 2015;21:4423-4426.

40. Cohen C, Benjamin M. Alcoholics and liver transplantation. The Ethics and Social Impact Committee of the Transplant and Health Policy Center. JAMA 1991;265:1299-1301.

41. Caplan AL, Coelho DH. The ethics of organ transplants: the current debate. New York: Prometheus Books, 1998.

42. Glannon W. Responsibility, alcoholism, and liver transplantation. J Med Philos 1998;23:31-49.

43. Lucey MR, Merion RM, Henley KS, Campbell DA Jr, Turcotte JG, Nostrant TT, et al. Selection for and outcome of liver transplantation in alcoholic liver disease. Gastroenterology 1992;102:1736-1741.

44. Soterakis J, Resnick R, Iber F. Effects of alcohol abstinence on survival in cirrhotic portal hypertension: report from the Boston InterHospital Liver Group. Lancet 1973;302:65-67.

45. Pande NV, Resnick RH, Yee W, Eckardt VP, Shurberg JL. Cirrhotic portal hypertension: morbidity of continued alcoholism. Gastroenterology 1978;74:64-69.

46. Dixon J, Welch HG. Priority setting: lessons from Oregon. Lancet 1991;337:891-894.

47. Chan HM, Cheung GM, Yip AK. Selection criteria for recipients of scarce donor livers: a public opinion survey in Hong Kong. Hong Kong Med J 2006;12:40-46.

48. Neuberger J. Public and professional attitudes to transplanting alcoholic patients. Liver Transpl 2007;13(11 Suppl 2):S65-S68.

49. Brown RS Jr. Transplantation for alcoholic hepatitis--time to rethink the 6-month "rule". N Engl J Med 2011;365:1836-1838.

50. Addolorato G, Mirijello A, Leggio L, Ferrulli A, D'Angelo C, Vassallo $G$, et al. Liver transplantation in alcoholic patients: impact of an alcohol addiction unit within a liver transplant center. Alcohol Clin Exp Res 2013;37:1601-1608.

51. Singal AK, Kamath PS, Gores GJ, Shah VH. Alcoholic hepatitis: current challenges and future directions. Clin Gastroenterol Hepatol 2014;12:555-564.

52. Testino $G$, Borro $P$, Ancarani $O$, Sumberaz A. Human carcinogenesis and alcohol in hepato-gastroenterology. Eur Rev Med Pharmacol Sci 2012;16:512-518.

53. Rice JP, Lucey MR. Should length of sobriety be a major determinant in liver transplant selection? Curr Opin Organ Transplant 2013;18:259-264.

54. Testino G, Burra P, Bonino F, Piani F, Sumberaz A, Peressutti R, et al. Acute alcoholic hepatitis, end stage alcoholic liver disease and liver transplantation: an Italian position statement. World J Gastroenterol 2014;20:14642-14651.

55. Im GY, Kim-Schluger L, Shenoy A, Schubert E, Goel A, Friedman $\mathrm{SL}$, et al. Early liver transplantation for severe alcoholic hepatitis in the United States--a single-center experience. Am J Transplant 2016;16:841-849.

56. Addolorato G, Bataller R, Burra P, DiMartini A, Graziadei I, Lucey $M R$, et al. Liver transplantation for alcoholic liver disease. Transplantation 2016;100:981-987.

57. Testino G, Leone S. Acute alcoholic hepatitis: a literature review and proposal of treatment. Minerva Med 2018;109:290-299.

58. Testino G, Scafato E, Patussi V. Acute alcoholic hepatitis. Recenti Prog Med 2017;108:366-373.

59. Zhu J, Chen PY, Frankel M, Selby RR, Fong TL. Contemporary policies regarding alcohol and marijuana use among liver transplant programs in the United States. Transplantation 2018;102:433-439.

60. Jesudian $A B$, Brown RS Jr. Acute alcoholic hepatitis as indication for liver transplantation. Curr Opin Organ Transplant 2016;21:107-110.

61. Germani G, Zanetto A, Ferrarese A, Russo FP, Senzolo M, Burra P. Orthotopic liver transplantation in alcoholic liver disease patients. Rev Recent Clin Trials 2016;11:253-259.

62. Lee BP, Chen PH, Haugen C, Hernaez R, Gurakar A, Philosophe B, et al. Three-year results of a pilot program in early liver transplantation for severe alcoholic hepatitis. Ann Surg 2016;265:20-29.

63. Daswani R, Kumar A, Sharma P, Singla V, Bansal N, Arora A. Role of liver transplantation in severe alcoholic hepatitis. Clin Mol Hepatol 2018;24:43-50.

64. Hong SK, Yi NJ, Kim HS, Ahn SW, Yoon KC, Kim H, et al. Korean patients undergoing deceased donor liver transplantation for alcoholic liver disease have non-inferior survival outcomes than for hepatitis $B$ virus: a real-world experience without minimum abstinence before transplantation. J Korean Med Sci 2017;32:919-925.

65. Gutmann T, Schneewind KA, Schroth U, Schmidt VH, Elsässer A, Land W, et al. Basics of a fair organ distribution: Medicine-Psychology-Law-Ethics-Sociology (MedR Series Medical Law). 8th ed. Berlin: Springer, 2003:9-78.

66. Prince MI, Hudson M. Liver transplantation for chronic liver disease: advances and controversies in an era of organ shortages. Postgrad Med J 2002;78:135-141.

67. Pereira SP, Howard LM, Muiesan P, Rela M, Heaton N, Williams R. Quality of life after liver transplantation for alcoholic liver disease. Liver Transpl 2000;6:762-768.

68. Kranzler HR, Armeli S, Wetherill R, Feinn R, Tennen H, Gelernter J, et al. Self-efficacy mediates the effects of topiramate and GRIK1 genotype on drinking. Addict Biol 2016;21:450-459.

69. Ferraguti G, Pascale E, Lucarelli M. Alcohol addiction: a molecular biology perspective. Curr Med Chem 2015;22:670-684.

70. Dick DM, Edenberg HJ, Xuei X, Goate A, Kuperman S, Schuckit M, 
et al. Association of GABRG3 with alcohol dependence. Alcohol Clin Exp Res 2004;28:4-9.

71. Dick DM, Bierut L, Hinrichs A, Fox L, Bucholz KK, Kramer J, et al. The role of GABRA2 in risk for conduct disorder and alcohol and drug dependence across developmental stages. Behav Genet 2006;36:577-590.

72. Dick DM, Plunkett J, Wetherill LF, Xuei X, Goate A, Hesselbrock V, et al. Association between GABRA1 and drinking behaviors in the collaborative study on the genetics of alcoholism sample. Alcohol Clin Exp Res 2006;30:1101-1110.

73. Dick DM, Agrawal A, Wang JC, Hinrichs A, Bertelsen S, Bucholz KK, et al. Alcohol dependence with comorbid drug dependence: genetic and phenotypic associations suggest a more severe form of the disorder with stronger genetic contribution to risk. Addiction 2007;102:1131-1139.

74. Dick DM, Wang JC, Plunkett J, Aliev F, Hinrichs A, Bertelsen S, et al. Family-based association analyses of alcohol dependence phenotypes across DRD2 and neighboring gene ANKK1. Alcohol Clin Exp Res 2007;31:1645-1653

75. Jones KA, Porjesz B, Almasy L, Bierut L, Goate A, Wang JC, et al. Linkage and linkage disequilibrium of evoked EEG oscillations with CHRM2 receptor gene polymorphisms: implications for human brain dynamics and cognition. Int J Psychophysiol 2004;53:75-90.

76. Luo X, Kranzler HR, Zuo L, Lappalainen J, Yang BZ, Gelernter J. $\mathrm{ADH} 4$ gene variation is associated with alcohol dependence and drug dependence in European Americans: results from HWD tests and case-control association studies. Neuropsychopharmacology 2006;31:1085-1095

77. Luo X, Kranzler HR, Zuo L, Wang S, Blumberg HP, Gelernter J. CHRM2 gene predisposes to alcohol dependence, drug dependence, and affective disorders: results from an extended case-control structured association study. Hum Mol Genet 2005;14:2421-2434.

78. Wang JC, Hinrichs AL, Stock H, Budde J, Allen R, Bertelsen S, et al. Evidence of common and specific genetic effects: association of the muscarinic acetylcholine receptor M2 (CHRM2) gene with alcohol dependence and major depressive syndrome. Hum Mol Genet 2004;13:1903-1911.

79. Wang JC, Hinrichs AL, Bertelsen S, Stock H, Budde JP, Dick DM, et al. Functional variants in TAS2R38 and TAS2R16 influence alcohol consumption in high-risk families of African-American origin. Alcohol Clin Exp Res 2007;31:209-215.

80. United Nations (UN). The Universal Declaration of Human Rights. UN web site, <http://www.un.org/en/documents/udhr/>. Accessed 20 Feb 2018

81. Hasanin M, Dubay DA, McGuire BM, Schiano T, Singal AK. Liver transplantation for alcoholic hepatitis: a survey of liver transplant centers. Liver Transpl 2015;21:1449-1452.

82. Marot A, Dubois M, Trépo E, Moreno C, Deltenre P. Liver transplantation for alcoholic hepatitis: a systematic review with metaanalysis. PLoS One 2018;13:e0190823

83. Lee BP, Mehta N, Platt L, Gurakar A, Rice JP, Lucey MR, et al. Outcomes of early liver transplantation for patients with severe alcoholic hepatitis. Gastroenterology 2018;155:422-430.e1.

84. Lee $B P$, Terrault NA. Early liver transplantation for severe alcoholic hepatitis: moving from controversy to consensus. Curr Opin Organ Transplant 2018;23:229-236.

85. Antonini TM, Guillaud O, Dumortier J, Dharancy S, Saliba F, Mathurin $\mathrm{P}$, et al. Impact of a first study of early transplantation in acute alcoholic hepatitis: results of a nationwide survey in French liver transplantation programs. Liver Transpl 2018;24:841-844. 